\title{
GAIA Fetal Growth Restriction Level of Diagnostic Certainty Terminology
}

National Cancer Institute

\section{Source}

National Cancer Institute. GAIA Fetal Growth Restriction Level of Diagnostic Certainty

Terminology. NCI Thesaurus. Code C128708.

A subset of terminology related to fetal growth restriction, developed by the Global Alignment of Immunization safety Assessment in pregnancy consortium to aid in monitoring and improving fetal and maternal outcomes. 